\title{
Association of gender and schizophrenia subtype with age at disease onset in a cohort from rural Turkey
}

\author{
Hasan Belli, MD* \\ Cenk Ural, MD* \\ Mustafa Solmaz, MD* \\ Mahir Akbudak, MD* \\ Mustafa Namli, MD** \\ Yılmaz Bayik, MD** \\ * Bagcilar Education And Research Hospital \\ Department of Psychiatry, Istanbul \\ ** Elazıg Mental Health Hospital \\ Department of Psychiatry, Elazıg \\ TURKEY
}

\begin{abstract}
Background and Objectives: This study was designed to investigate the association of the gender and subtype diagnosis with the onset age of the disease, marriage, reproductive rates in the schizophrenic inpatients.

Methods: Total of 463 patients (329 males and 134 females) hospitalized with the diagnosis of schizophrenia according to DSM-IV criteria and who were between 15-65 years of age were included in the study. We evaluated the age, gender, marital status, number of children, onset of the disease and subtype of schizophrenia.

Results: Mean of onset of the disease score was higher statistically in the females (27.6 \pm 4.3) than the males $(23.7 \pm 3.9)(\mathrm{p}<0.05)$ in our study. The paranoid subtype was the commonest, while women were more likely to be married than men, men had more children than women; and the paranoid subtype were more likely to be married than the other groups.

Conclusions: Onset age of schizophrenia was four years higher in the women than in men and that the rates of the schizophrenia subtypes were consistent with those detected in the other studies demonstrates that these rates were determined by neurobiological mechanisms rather than socio-cultural factors.
\end{abstract}

Received: 25 November 2010

Revised: 9 May 2011

Accepted: 30 May 2011 


\section{Introduction}

Loranger ${ }^{1}$ reported that the mean age at onset of schizophrenia in men was approximately 5 years earlier than that of women. Goldstein et al. ${ }^{2}$ used the DSM-III criteria, and found that the mean age at onset 24.3 for men with schizophrenia and 27.9 for women with schizophrenia. Appllying the Research Diagnostic Criteria ${ }^{3}$ to a Nigerian sample of schizophrenia patients, Gureje ${ }^{4}$ found that the mean age at onset illness was 23.5 for men and 26.4 years for women. $\mathrm{He}$ concluded that the gender difference in the age at onset of schizophrenia is present across cultures, implying a biological rather than a social etiology. In a a better designed study of Nigerian schizophrenia patients, Ohaeri ${ }^{5}$ reported similar findings. Gruenberg et al. ${ }^{6}$, in a study of reliability and concordance of the subtypes according to four major diagnostic systems, showed that the age at onset for the paranoid subtype was significantly later than for the disorganized and the undifferianted subtypes.

It is generally accepted that patients with schizophrenia have lower marital and fertility rates than the rest of the general population and indeed than patients with other psychiatric conditions ${ }^{7,8}$. There has been a long-held belief that these lower rates were occasioned by the deterioration in social life, particularly for catatonic and hebephrenic patients ${ }^{9}$. The severity of ilness and timing of marriage ${ }^{10}$ were also thought to be crucial. This would especially impact on males, who tend to have earlier age of onset and more protracted course with worse outcome ${ }^{11}$, in a reproductive culture informed by male initiative.

This study was designed to investigate the association of the gender and subtype diagnosis with the onset age of the disease, marriage, reproductive rates in the schizophrenic inpatients.

\section{Participants and methods}

This study was performed in Elazı̆̆ Mental Hospital It is a regional hospital situated in the Eastern-Southeastern region of the country and provides services to 22 cities of the region. Total of 463 patients (329 males and 134 females) hospitalized with the diagnosis of schizophrenia according to DSM-IV criteria $^{12}$ and who were between 15-65 years of age were included in the study.

Required information was primarily obtained from relatives and then from the patients. We evaluated the age, gender, marital status, number of children, onset of the disease and subtype of schizophrenia. All data were collected through face-to-face interviews or reviews of hospital records. A group of two people consisting of 1 psychiatrist and 1 psychologist evaluated each patient.

The difference between two groups in definitive characteristics was studied with $\chi^{2}$ test, groups of more than two were studied using the Kruskal-Wallis method and the relationship between groups was investigated using Spearman correlation analysis. The level of significance was defined as $\mathrm{p}<0.05$.

\section{Results}

Table 1 shows the distribution of the 463 patients in the two sex of schizophrenic disorders. Among this group, 329 were male and 134 were female. The mean age of our patients was $36.49 \pm 10.09$ years. 142 of the total 463 patients were married $(30.7 \%)$. 95 male patients were married $(28.9 \%)$ and 47 female patients were married $(35.1 \%)$. The male patients were significantly less likely to be married than the female patients $\left(\chi^{2}=31.66, \mathrm{P}\right.$ $<0.001) .45 .1 \%$ of total patients did not have 
Table 1

Marital status, number of children and age at onset of the disease according to gender differences

\begin{tabular}{lcccccccc} 
& \multicolumn{2}{c}{ Males } & \multicolumn{2}{c}{ Females } & \multicolumn{2}{c}{ Total } \\
\hline Variants & $\mathrm{n}$ & $\%$ & $\mathrm{n}$ & $\%$ & $\mathrm{n}$ & $\%$ & $\chi^{2}$ & $\mathrm{P}$ \\
\hline Gender & 329 & 71.1 & 134 & 28.9 & 463 & 100 & & \\
\hline Marital status & & & & & & & 31.66 & $<0.001$ \\
\hline Married & 95 & 28.9 & 47 & 35.1 & 142 & 30.7 & \\
\hline Single & 218 & 66.3 & 61 & 45.5 & 279 & 60.3 & \\
\hline Divorced & 12 & 3.6 & 15 & 11.2 & 27 & 5.8 & \\
\hline Widow & 4 & 1.2 & 11 & 8.2 & 15 & 3.2 &
\end{tabular}

\section{Number of children}

\begin{tabular}{|c|c|c|c|c|c|c|c|c|}
\hline Absent & 43 & 38.7 & 40 & 54.8 & 83 & 45.1 & 18.91 & $=0.002$ \\
\hline 1 & 6 & 5.4 & 9 & 12.3 & 15 & 8.2 & & \\
\hline 2 & 19 & 17.1 & 5 & 6.8 & 24 & 13.0 & & \\
\hline 3 & 11 & 9.9 & 5 & 6.8 & 16 & 8.7 & & \\
\hline 4 & 6 & 5.4 & 9 & 12.3 & 15 & 8.2 & & \\
\hline 5 and above & 26 & 23.4 & 5 & 6.8 & 31 & 16.8 & & \\
\hline Total & 329 & 71.1 & 134 & 28.9 & 463 & 100 & & \\
\hline Age at onset of the disease & & & & & & & 64.03 & $<0.001$ \\
\hline 25 and below & 241 & 73.3 & 44 & 32.8 & 285 & 61.6 & & \\
\hline 26 and above & 88 & 26.7 & 90 & 67.2 & 178 & 38.4 & & \\
\hline
\end{tabular}

any children. Whereas $54.8 \%$ of married women did not have any children, $43 \%$ of married men did not have any children. Mean of onset of the disease score was higher statistically in the females $(27.6 \pm 4.3)$ than the males $(23.7 \pm 3.9)(\mathrm{p}<0.05)$ in our study.

As presented in Table 2, 62.4\% of patients were paranoid, $27.2 \%$ of them were disorganized, $8.2 \%$ of them were residual and $6.7 \%$ of them were undifferentiated subtypes. The ratio of married patients was still high in the paranoid group. whereas the ratio of singles were higher in the other three groups $(t=$
52.31, $\mathrm{p}<0.001)$. The number of children was lower in the disorganized subtype and higher in other subtypes. The onset of the disease was before 25 years of age in the majority of patients in the three subtypes apart from the residual group $(\mathrm{t}=13.57, \mathrm{p}=0.004)$. 118 of these 289 patients $(40.8 \%)$ were married. $57.1 \%$ of the patients with paranoid sub-type had at least one child. This rate was $30.4 \%$ for the disorganized subtype and $56.2 \%$ for the residual subtype. In other words, the marriage rate was lowest in the patients with undifferentiated subtype. 
Table 2

Marital status, number of children and age at onset of the disease of patients according to subtype of schizophrenia

Type of schizophrenia Paranoid Disorganized Residual Undifferentiated

\begin{tabular}{lcccccc}
\hline Variants & $\mathrm{n}(\%)$ & $\mathrm{n}(\%)$ & $\mathrm{n}(\%)$ & $\mathrm{n}(\%)$ & $\chi^{2}$ & $\mathrm{P}$ \\
\hline Total & $289(62.4)$ & $105(22.7)$ & $38(8.2)$ & $31(6.7)$ & & \\
\hline Marital status & & & & & 52.31 & $<0.001$ \\
\hline Married & $118(40.8)$ & $7(6.7)$ & $12(31.6)$ & $5(16.1)$ & & \\
\hline Single & $149(51.6)$ & $82(78.1)$ & $22(57.9)$ & $26(83.9)$ & & \\
\hline Divorced & $14(4.8)$ & $11(10.5)$ & $2(5.3)$ & - & & \\
\hline Widow & $8(2.8)$ & $5(4.8)$ & $2(5.3)$ & - & & \\
\hline Number of children & & & & & & \\
\hline Absent & $60(42.9)$ & $16(69.6)$ & $7(43.8)$ & - & & \\
\hline 1 & $8(5.7)$ & $4(17.4)$ & $1(6.3)$ & $2(40.0)$ & & \\
\hline 2 & $17(12.1)$ & $1(4.3)$ & $5(31.3)$ & $1(20.0)$ & & \\
\hline 3 & $16(11.4)$ & - & - & - & & \\
\hline 4 & $15(10.7)$ & - & - & & & \\
\hline 5 and above & $24(17.1)$ & $2(8.7)$ & $3(18.8)$ & $2(40.0)$ & & \\
\hline Age at onset of the disease & & & & & & \\
\hline 25 and below & $172(59.5)$ & $66(62.9)$ & $19(50.0)$ & $28(90.3)$ & & \\
\hline 26 and above & $117(40.5)$ & $39(37.1)$ & $19(50.0)$ & $3(9.7)$ & & \\
\hline
\end{tabular}

\section{Discussion}

The cities included in the study from the east regions represent the socioeconomically undeveloped regions of Turkey ${ }^{13}$. The people living here commonly use another language as well as the official language. The Kurdish language is spoken commonly in the daily life in this region. The patients in the study and their relatives were interviewed by a translator.

Mean of onset of the disease score was higher statistically in the females $(27.6 \pm$ $5.3)$ than the males $(23.7 \pm 4.9)(\mathrm{p}<0.05)$ in our study. The paranoid subtype was the commonest, while women were more likely to be married than men, men had more children than women; and the paranoid subtype were more likely to be married than the other groups. Many Western studies have shown that men develop schizophrenia on average four to six years earlier than wo$m^{14}$. This difference has also been reported in a rural Chinese epidemiological survay $^{15}$. In our study we showed that the disease started in females approximately four years later than in males. This finding was consistent with the information that schizophrenia started earlier in males ${ }^{16-18}$. We did not find any gender difference in the subtypes of schizophrenia and this finding was consistent with other studies ${ }^{16,19}$. Despite socio-cultural differences, the fact that 
the onset age of schizophrenia was four years higher in the women than in men and that the rates of the schizophrenia subtypes were consistent with those detected in the other studies demonstrates that these rates were determined by neurobiological mechanisms rather than socio-cultural factors. $\mathrm{Nu}-$ merous studies in economically advenced European nations, as well as Japan and USA have reported on gender-related variations in procreation among individuals with schizophrenia. It has been noted consistently that the unmarried state and childlessness are more common among male patients ${ }^{20-22}$. Although the rate of marriage was higher among women, married men had more children than women in our study. Cultural peculiarities may be significant in this contradiction, and therefore the effect may tend to vary across ethnicity and culture.

\section{References}

1. Loranger AW. Sex differences in age at onset of schizophrenia. Arch Gen Psychiatry 1984; 41:157-161.

2. Golstein JM, Tsuang MT. Gender and schizophrenia: an introduction and synthesis of findings. Schizophr Bull 1990; 16: 179-183.

3. Spitzer RL, Endicott J, Robins E. Diagnostic criteria: rationale and reliability. Arch Gen Psychiatry 1978; 35: 773-782.

4. Gureje O. Gender and schizophrenia: age at onset and sociodemo-graphic attiributes. Acta Psychiatr Scand 1990; 83: 402-405.

5. Ohaeri JU. Age at onset in a cohort of schizophrenics in Nigeria. Acta Psychiatr Scand 1992; 86: 332-334.

6. Gurenberg AM, Kendler KS, Tsuang MT. Reliability and concordance in the subtyping of schizophrenia. Am J Psychiatr 1985; 142: 1355-1358.

7. Nanko S, Moridaria J. reproductive rates in schizophrenic outpatients. Acta Psychiatr Scand 1993; 87: 400-404.

8. Saugstad LF. Social class, marriage and fertility in schizophrenia. Schizophr Bull 1989; 15: 9-43.

9. Kallman FJ. The genetics of schizophrenia. New York: J.J. Augustin Publisher; 1938.
10. Bleuler M. The schizophrenic disorders: Long term patient and family studies. New Haven: Yale University Press; 1978.

11. Hafner H, Maurer K, Leffler V, Riecher-Rossier A. The influence of age and sex on the onset and early course of schizophrenia. Br J Psychiatry 1993; 162: 80-86.

12. Amerikan Psikiyatri Birligi. Mental Bozukluklann Tanisal ve Sayimsal El Kitabı. Dördüncü baski (DSM-IV). In: Koroglu E (ed). Ankara: Hekimler Yaym Birligi; 1996. p. 218-227.

13. Republic of Turkey, Prime Ministry, State Planning Organization. The Project of East Anatolia. Ankara; 2000.

14. Hafner H, Heiden W, Behrens S, Gattaz WF, Hambrecht M, Löffler W, et al. Causes and consequences of the gender difference in age at onset of schizophrenia. Schizophr Bull 1998; 24: 99-113.

15. Ran MS, Xiang MZ, Li SX, San YH, Huang MS, Li SG, et al. Prevalence and course of schizophrenia in a Chinese rural area. Aust N Z J Psychiatry 2003; 37: 452-457.

16. Usall J, Araya S, Ochoa S, Busquets E, Gost A, Marquez M. Gender differences in a sample of schizophrenic outpatients. Compr Psychiatry 2001; 42: 301-305.

17. Angermeyer MC, Goldstein JM. Gender differences in schizophrenia rehospitalization and community survival. Psychol Med 1989; 19: 365-382.

18. Kaplan HI, Sadock BJ. Schizophrenia. In: Kaplan HI, Sadock BJ (eds.). Synopsis of Psychiatry: Behavioral Sciences/Clinical Psychiatry, $8^{\text {th }}$ edition. Giza: Mass Publishing; 1998. p. 456-491.

19. Usall J, Haro JM, Ochoa S, Marquez M, Araya S. Influenca of gender on social outcome in schizophrenia. Act Psychiatr Scand 2002; 106: 337-342.

20. Nimgaonkar VL, Ward SE, Agarde M. Fertilty in schizophrenia: results from contemporary US cohort. Acta Psychiatr Scand 1997; 95: 364-369.

21. Nimgaonkar VL. Reduced fertility in schizophrenia: here to stay? Acta Psychiatr Scand 1998; 98; 348-353.

22. Haukka J, Suvisaari J, Lonnqvist J. Fertility of patients with schizophrenia, their siblings, and the general population; a cohort study from 1950 to 1959 in Finland. Am J Psych 2003; 160: 460-463.

Author for correspondence:

Dr Hasan Belli

Bağcılar Eğitim ve Ara Ştırma Hastanesi

Bağcılar/ Istanbul, Turkey

Fax: +902124404002

Tel: +90 2124404000

E-mail: www.hasan.belli@hotmail.com 